\title{
EDUCAÇÃO AMBIENTAL NAS SOCIEDADES INDÍGENAS BRASILEIRAS: UMA BREVE ANÁLISE
}

\author{
F. X. S. Araújo'; E. S. Santos ${ }^{2}$, L. U. Esteves ${ }^{2}$ e T. L. Silva ${ }^{2}$ \\ ${ }^{1,2}$ Programa de Pós-Graduação em Direito Ambiental e Políticas Públicas - Universidade Federal do Amapá \\ E-mail: fabiuxavier@gmail.com ${ }^{1}$
}

Artigo submetido em outubro/2013 e aceito em novembro/2013

\section{RESUMO}

Este trabalho teve por objetivo apresentar um breve histórico e abordagem sobre a Educação Ambiental Indígena no Brasil, desde os tempos de Colônia, perpassando por leis internacionais, até as políticas públicas contemporâneas. Investigou se a Educação Ambiental Indígena atual está mais voltada para a questão escolar formal ou ambiental. Nesse contexto, abordou aspectos que visam melhorar a Educação
Ambiental em terras indígenas. A metodologia utilizada na pesquisa focou-se na abordagem qualitativa, com procedimentos técnicos da pesquisa bibliográfica e documental. Os resultados indicaram que a Educação Ambiental Indígena se encontra mais voltada para uma educação escolar, daí a necessidade de mudança no paradigma atual, readequando-o à Educação Ambiental.

PALAVRAS-CHAVE: Educação, Ambiental, Indígena, Brasil.

\section{ENVIRONMENTAL EDUCATION IN BRAZILIAN INDIGENOUS SOCIETIES: A BRIEF REVIEW}

\begin{abstract}
This work aims at presenting a brief history and approach to Indigenous Environmental Education in Brazil from Portuguese colony, passing by international law, to the contemporary public policy. It was investigated whether the Indigenous education nowadays is more focused on formal education or Environmental Education. In this paradigm, it was dealt with issues to improve Environmental Education in
\end{abstract}

indigenous lands. The methodology used in this research focused on the qualitative approach, with technical procedures from bibliographical and desk research. The results indicated that the Indigenous Environmental Education is more focused on formal school education, hence the need for change in the current paradigm, adapting it to environmental education.

KEYWORDS: Indigenous, Environmental, Education, Brazil. 


\section{EDUCAÇÃO AMBIENTAL NAS SOCIEDADES INDÍGENAS BRASILEIRAS: UMA BREVE ANÁLISE}

\section{INTRODUÇÃO}

Atualmente, o Brasil possui 216 sociedades indígenas, somando 350 mil indivíduos, onde certas etnias ou tribos possuem grupos de 200 a 20,000 mil pessoas. Somando 739 terras indígenas, as quais 315 ainda não foram demarcadas. Contemporaneamente, o número de índios está crescendo em ritmo acelerado, principalmente em áreas urbanas e suburbanas, onde, agora, encontram-se os "novos índios": "[...] que perderam parte de sua identidade cultural (a língua na sua maioria) e agora lutam por sua autodeterminação étnica e pela posse de suas terras." (SILVA; RABELO; RODRIGUEZ, 2011, p. 38).

As políticas públicas em prol das sociedades indígenas versando sobre a posse de suas terras, sua autodeterminação étnica e cultural só iniciaram, no Brasil, a partir do século XX. A Lei № 9.795 de 27 de abril de 1999 regula a Política Nacional de Educação Ambiental - PNEA. A estruturação e aplicação dessas políticas levaram a educação escolar indígena a progressos significativos. Em âmbito federal, por exemplo, ela é coordenada e exercida pelo Ministério da Educação e Cultura - MEC. (SILVA; RABELO; RODRIGUEZ, 2011, p. 40).

Reigota (2012, p. 13) ao tratar de Educação Ambiental é enfático em não separar sua definição dos limites da educação política, das primícias das relações políticas, econômicas, sociais e culturais entre a humanidade e a natureza, rompendo com todas as ideologias que impedem o exercício da participação livre, consciente e democrática de todos.

Assim, o objetivo deste trabalho é verificar por meio de um estudo bibliográfico como se encontra a Educação Ambiental Indígena atualmente, considerando os seguintes preceitos: a diversidade cultural, a pluralidade de indivíduos, a compreensão, a condição humana, a cidadania planetária, a ética do gênero humano, a construção de um conhecimento de natureza transdisciplinar e que envolva as relações indivíduo-sociedade-natureza.

\section{MATERIAL E MÉTODOS}

Quanto a sua natureza, esta é uma pesquisa aplicada, com abordagem qualitativa e fins exploratórios. Para analisar as literaturas publicadas na área, o procedimento técnico utilizado adveio da pesquisa bibliográfica e documental. O método histórico subsidiará a investigação dos acontecimentos bibliográficos e documentais que influenciam o problema no presente.

\section{RESULTADOS}

\section{Educação ambiental indígena: Um breve histórico}

A educação indígena no Brasil, do século XVI ao XX, foi fundamentada pela catequização ou integração forçada dos índios na sociedade, acentuando a imposição de valores e a negação de identidades e culturas diferenciadas. Com a expulsão dos jesuítas no ano de 1779, as ações educativas estagnaram. (BURATTO, 2007, p. 02). Nesse sentido, o Marquês de Pombal, por meio 
de decreto, proibiu o ensino das línguas indígenas nas escolas, impondo somente o ensino da Língua Portuguesa aos índios.

O uso da Língua geral que subsiste após à lei pombalina, aparentemente confirmava a relação de reciprocidade, porém não livrou a população indígena de abusos, arbitrariedades e violências. Estas, que ao longo desse período, através da língua do colonizador, frequentemente associada a educação religiosa e, algumas vezes, à instrução nas primeiras letras, impôs compulsoriamente novas formas de consumo e de produção alterando, sobre maneira, o universo cultural dessas populações .(PUPPI, 1996, p. 17)

Buratto (2007) esclarece que oito anos após a proclamação da independência, o Senado Federal emitiu uma resolução que permitia o acesso dos índios à educação escolar e ao serviço militar. Mas foi somente a partir da Proclamação da República em 1889 que os povos indígenas passaram a ter direito a instrução. De 1910 a 1966, as ações governamentais foram centradas na educação indígena profissional. Neste período foram formados os intérpretes nas línguas indígenas, apoiados pela Comissão Rondon, como parte da política integracionista da época. Ainda nesse período, o Serviço de Proteção ao Índio - SPI instituiu as reservas indígenas.

No ano de 1967, o governo cria a Fundação Nacional do Índio - FUNAI, e esta passa a substituir a SPI. A FUNAI, então, passa a assumir oficialmente o controle do modelo de educação bilíngue que foi proposto pelo Summer Institute of Linguistics - SIL, instalado no Brasil em 1956. A parceria entre a FUNAI e o SIL objetivava codificar as línguas e ensiná-las nas escolas. Em 19 de dezembro de 1973, foi criado Estatuto do Índio, por meio da Lei № 6.001, que garantiu a alfabetização dos índios na língua do grupo que pertencesse. (BURATTO, 2007).

Ferreira (2001) diz que a partir da década de 80, quando iniciaram as lutas democráticas no Brasil, os povos indígenas também se mobilizaram e decidiram definir e autogerir os processos educacionais formais. Todavia, Burato (2007, p. 07) enfatiza que uma grande mudança foi verificada a partir da Constituição promulgada em 05 de outubro 1988, que trouxe um capítulo denominado "Dos Índios", onde no título III trazia "Da ordem social":

Art. 231 - São reconhecidas aos índios suas organizações sociais, costumes, língua, crenças e tradições e o direito originário sobre as terras que tradicionalmente ocupam, competindo à União demarcá-las, proteger e fazer respeitar todos seus bens. (BRASIL, 1988, p.150).

A Carta Magna da Legislação brasileira permitia assim, além do direito de permanecerem índios, a manutenção da identidade cultural, abrindo entendimento para que a educação indígena pudesse abarcar a valorização das línguas, os saberes e as tradições indigenistas.

Art. 210. Serão fixados conteúdos mínimos para o ensino fundamental, de maneira a assegurar formação básica comum e respeito aos valores culturais e artísticos, nacionais e regionais.

$\S 2$ - - O ensino fundamental regular será ministrado em língua portuguesa, assegurada às comunidades indígenas também a utilização de suas línguas maternas e processos próprios de aprendizagem. 
O Decreto presidencial № 26, de 04 de fevereiro de 1991, atribuiu ao Ministério da Educação e Cultura - MEC a responsabilidade de integrar a educação indígena aos sistemas de ensino regular, até então, tarefa da FUNAI. A portaria ministerial № 559/91 normatizou como o MEC desempenharia as novas funções e criou os Comitês de Educação Escolar Indígena, que assessorava a Coordenação Geral de Apoio às Escolas Indígenas, criada pelo MEC.

O Comitê de Educação Escolar Indígena era constituído por linguistas, antropólogos, indígenas e técnicos de diversos órgãos do Governo. Esse Comitê assessorou o MEC na definição da política nacional de educação escolar indígena, mas foi substituído por uma Comissão Nacional de Professores Indígenas, e formou, assim, o primeiro órgão composto por índios para o assessoramento da União. (BURATTO, p. 08, 2007).

As conquistas na legislação brasileira levaram as sociedades indígenas a se organizarem e romperem com o processo de denominação que perdurava por vários séculos. Como consequência, muitos setores governamentais e não governamentais entraram em ação. Foram criadas entidades de apoio que se articularam e exigiram que fossem garantidos os direitos indígenas na legislação brasileira.

Em 1996, a Lei № 9.394, também chamada de Diretrizes e Bases da Educação Nacional, fez menção a Constituição Brasileira quando trata das questões indígenas:

Art. 32. § 3o 0 ensino fundamental regular será ministrado em língua portuguesa, assegurada às comunidades indígenas a utilização de suas línguas maternas e processos próprios de aprendizagem.

Art. 78. O Sistema de Ensino da União, com a colaboração das agências federais de fomento à cultura e de assistência aos índios, desenvolverá programas integrados de ensino e pesquisa, para oferta de educação escolar bilíngue e intercultural aos povos indígenas, com os seguintes objetivos [...].

Percebe-se por meio dos artigos supracitados o reconhecimento dos direitos das sociedades indígenas principalmente quanto à recuperação e preservação de sua cultura, acesso às informações, conhecimentos técnicos e científicos. A União é a responsável pelo apoio técnico e financeiro a esse sistema educacional, porém, é necessário se analisar a educação indígena tal como vem sendo conceitualizada e implementada já há quase vinte anos.

\section{Educação escolar ou Educação ambiental indígena?}

A educação indígena é entendida, conforme Ribeiro (2000, p. 08), como sendo "um conjunto dos processos de socialização e transmissão de conhecimentos próprios e internos a cada cultura indígena". Contudo, conforme assevera a autora, tudo o que vem sendo praticado até o momento não passa de educação escolar, pois tem como referência o sistema formal existente na sociedade não indígena, baseado no letramento e na escola.

Ribeiro (2000) nos diz que a educação indígena no Brasil, ao longo da história, sempre andou ao lado da religião e das doutrinas humanitárias e que ocorreu, na verdade, foi um processo de aculturação. Mesmo com as conquistas alcançadas na última constituição referentes aos direitos indígenas, a dificuldades se encontram na compatibilização das conquistas com o 
ideário positivista que impregna a relação com a cultura indígena. Ainda conforme a teórica, há, portanto:

[...] uma evidente tensão entre princípios que afirmam a pluralidade cultural linguística e que defendem não só o respeito, mas também a alimentação dessa pluralidade e uma visão que alimenta a hegemonia de uma cultura e de uma língua.

Em suma, os anos 70 representaram a catequização e socialização dos índios na sociedade brasileira, pois, até então, a tradição indígena se baseava na dependência e subordinação da terra. A ideologia da época era integrar e socializar o índio, uma vez que este era entendido com condição inferior a da cultura ocidental cristã. "O Estado tutor jamais se preocupava com a educação especificamente indígena e sim com a educação voltada para a integração". RIBEIRO (2000, p. 03).

A partir da década de 90, o modelo brasileiro de educação indígena ganhou força com a criação da FUNAI e com as Secretárias Estaduais e Municipais que adotaram as Escolas Rurais, urbanas e das missões religiosas, a fim de tornarem os índios bilíngues, leitores do evangelho trazido nas línguas maternas. Contudo, o ensino continuava distante da realidade dos índios.

No meio deste paradigma, surgiram as propostas de escolas voltadas para a formação dos professores indígenas, com currículos específicos. Tais escolas foram implantadas por associações, lideranças indígenas ou a partir de interlocução entre pesquisadores e comunidades indígenas. O ano de 1994 marca a data em que as Universidades Brasileiras aliam-se a organizações não governamentais e tomam a iniciativa de formular políticas voltadas para as questões indigenistas.

Em 2001, por meio da Lei № 10.172, surge o Referencial Curricular Nacional para as Escolas Indígenas (RCNEI), que tratou da educação e do desenvolvimento curricular paras as escolas e à formação de professores indígenas. Já a resolução no 3/99, do Conselho Nacional de Educação, em 1999, estabeleceu as diretrizes nacionais para o funcionamento das Escolas Indígenas. Conforme Silva; Rabelo; Rodriguez (2011, p. 41), as principais normativas propostas pelo MEC para as Escolas Diferenciadas Indígenas foram:

- Referencial Curricular Nacional para as Escolas Indígenas. Brasília: MEC-SEF, 1998;

- Referências para formação de professores indígenas. Brasília: MEC, 2002;

- Diretrizes para a Política Nacional de Educação Escolar Indígena;

- Cadernos de Educação Básica. Série Institucional, Brasília: MEC, 1994.

Ainda consoante ao teórico supracitado, o Censo Escolar Indígena do ano de 2005, indicou que o país contava com 1.666 Escolas Diferenciadas Indígenas, somando 4.000 professores, $75 \%$ destes, autóctones e $25 \%$ não indígenas.

Segundo Silva; Rabelo; Rodriguez (2011, p. 46), a Educação Ambiental é um instrumento de educação formal e informal que ajuda as comunidades a convirem melhor em seu meio. Ela pode ser direcionada tanto aos moradores quanto aos visitantes da área. Sua aplicação pode ser por meio de atividades curriculares ou de maneira informal, com cursos e oficinas que enriqueçam os saberes culturais e possibilitem uma melhor relação com a natureza. 
Nesta concepção, o ecoturismo seria uma boa alternativa que adequa-se plenamente às terras indígenas, pois é pouco impactante quando bem conduzida, explora os recursos paisagísticos, contribui para conservação ambiental e proteção cultural. A Educação Ambiental e o Ecoturismo deveriam formar parcerias e caminharem juntos na busca de um desenvolvimento local com base sustentável. Silva; Rabelo; Rodriguez (2011) propõe as seguintes alternativas:

- Fortalecimento do papel social e do poder político e econômico da comunidade por meio de cursos e oficinas de caráter prático e pedagógico;

- Definição de Áreas de Preservação Permanente de uso conservacionista e específico, tendo como base uma planificação participativa e comunitária;

- Preservação e resgate dos valores e saberes culturais a serem efetivados pelos próprios índios, com uma devida orientação científica;

- Desenvolver uma ética sustentada em valores culturais, sociais e ambientais por meio de seminários, discussões e apresentações participativas;

- Promover uma Educação Ambiental apoiada nos valores culturais, sociais e ambientais, buscando reforçar a identidade étnica e comunitária, de forma a promover a sustentabilidade;

- Obter o desenvolvimento de capacidades de gestão possibilitando a evolução de atividades econômicas sustentáveis: pesca, mariscagem, extrativismo vegetal, horticultura, agricultura orgânica, permacultura, ecoturismo e turismo cultural, e ainda cooperativismo que assuma uma denominação de origem, que beneficie todos os integrantes da comunidade.

Os direitos estabelecidos na Lei de Diretrizes e Bases de 1996 e nas legislações subsequentes enfatizam que a educação indígena deverá ter um tratamento diferenciado em relação às outras escolas do sistema, determinado pela prática da interculturalidade e bilinguismo, porém esses encaminhamentos, além de não estarem bem discutidos e compreendidos, estão distantes de se efetivar na prática, vários são os entraves burocráticos que adiam o cumprimento da legislação. (BURATTO, 2007).

\section{Usando novas tecnologias para mediar a Educação Ambiental Indígena}

O uso de novas tecnologias para auxiliar a Educação Ambiental Indígena possui o objetivo de propiciar interações didáticas diferenciadas, possibilitando a melhor formação e capacitação de professores e alunos, o melhor contato e integração da educação diferenciada indígena com a educação ambiental, buscando incluir e integrar aspectos relativos à cultura e ao meio ambiente, superando paradigmas vigentes impostos pela visão mecanicista da pedagogia tradicional e oficialista, rompendo com os modelos que privilegiam a reprodução desinteressada e distante da realidade que permeia o espaço real e vivido como um todo. (SILVA; RABELO; RODRIGUEZ, 2011).

As tecnologias devem atuar com o objetivo de abarcar os problemas ambientais e sociais atuais, realizando a contextualização com os processos históricos que formulam o quadro atual da sociedade, devem estar em harmonia e cooperação entre as comunidades indígenas e o meio ambiente, auxiliando as medidas preventivas e senso crítico.

Destaca-se, consoante a Silva; Rabelo; Rodriguez (2011, p. 72), é que as sociedades indígenas estão passando por um processo de perda de seus valores originais, com extinção 
quase total de seus costumes e modos de vida dos antepassados. Entre outros fatos, este paradigma pode ser explicado devido à aceleração e a incrível troca de informações geradas pelos veículos de comunicação em massa que promovem a desvalorização quanto ao que diz respeito às culturas indígenas tradicionais e seus saberes e costumes. indígenas:

Diversas são as tecnologias que podem ser trabalhadas dentro das comunidades

a) Projeção de vídeos - Exibição de documentários voltados para a temática ambiental, reportagens que desperte a percepção das pessoas e se torne uma atividade conscientizadora e lúdica;

b) Cursos - Objetivam principalmente formar agentes multiplicadores que possam repassar os conhecimentos que versem sobre a importância dos ecossistemas naturais na manutenção do equilíbrio ambiental. Silva; Rabelo; Rodriguez (2011) propõe os seguintes cursos: Artesanato, Meio Ambiente, Turismo e Dinâmica Litorânea, Ecossistema, Natureza e Sociedade, Condutores de Trilhas Ecológicas e Educação Ambiental;

c) Oficinas - Atividades de caráter prático que buscam abarcar assuntos relacionados aos recursos hídricos, reciclagem de resíduos sólidos, impactos ambientais, metodologias para uma educação ambiental comunitária, ecologia de ecossistemas. Temas que podem ser trabalhados: A questão da água no século XXI, o lixo e seus impactos ambientais, metodologia da Educação Ambiental, Elaboração de pulseiras e colares, pintura corporal, artesanato com papel reciclado;

d) Outras tecnologias que podem ser abordadas são: folders, workshops, palestras, planilhas eletrônicas, cursos de informática em geral, entre outros. Todas as tecnologias devem ser usadas com o intuito de integrar sustentabilidade social, econômica e ambiental.

É necessário que haja a ruptura do modelo que privilegia a imposição, a punição e a segregação imposta pelo ensino escolar bancário. A Educação Ambiental Indígena deve provocar a mudança de hábitos e comportamentos, despertando uma nova consciência ambiental. (SILVA; RABELO; RODRIGUEZ, 2011).

\section{Salas Verdes: Uma nova perspectiva na Educação Ambiental Indígena}

A Sala Verde é um projeto que tem suas origens na Diretoria de Educação Ambiental do Ministério do Meio Ambiente (DEA/MMA). Seu objetivo é promover o incentivo para implantação de espaços socioambientais pelo país, instituindo Centros de Informação e Formação Ambiental, bem como potencializar espaços, estruturas e iniciativas similares já existentes em diversas instituições, por exemplo, órgãos públicos, privados e do terceiro setor.

A sala verde é um ambiente dinâmico, nela, acontecem leituras, acesso e vista de documentos, participação de atividades educacionais e na promoção dos eventos, além de outras atividades.

A capacidade articuladora das Salas Verdes a faz ser considerada potencialmente como um Centro de Educação Ambiental (CEA). Ela possui a capacidade de fomentar e de promover processos educacionais voltados à questão ambiental a partir da disponibilização de informações, 
da promoção de eventos e de outras atividades de caráter cultural e ambiental, dentre elas: exposições, mostras, seminários, peças teatrais etc. (SILVA; RABELO; RODRIGUEZ, p. 104, 2011).

É notório ressaltar a ação da Universidade Federal do Ceará (UFC), por meio de seu Departamento de Geografia, desenvolveu uma Sala Verde com os seguintes objetivos:

- Realizar cursos, oficinas, palestras e projetar filmes educativos;

- Efetivar exposições temáticas e promover ações integradas de Educação Ambiental;

- Participar de ações de enraizamento da Educação Ambiental na região;

- Divulgar e participar de encontros, seminários e oficinas sobre a Agenda 21;

- Participar e ampliar programas educativos nas áreas de consumo sustentável;

- Divulgar a importância do saneamento básico;

- Esclarecer a Ecologia dos Ecossistemas costeiros;

- Promover o desenvolvimento de metodologias de estudos e pesquisas ambientais;

- Elaborar materiais educativos e outros instrumentos para a capacitação em Educação Ambiental;

- Estimular o intercâmbio de informações, experiências e iniciativas com as demais Salas Verdes, com os cursos de Graduação, Pós-Graduação e demais entidades da sociedade civil (ONG's, Fóruns, Associações comunitárias) e entidades vinculadas aos entes federados (OEMA's, IBAMA, SEMACE, SEMAM, CIEA, entre outras).

- Ampliar o acesso à informação e suas atividades de extensão universitária;

- Promover um conjunto de ações efetivas para uma consciência crítica e estimular o enfretamento das questões ambientais e sociais.

Segundo Silva; Rabelo; Rodriguez (2011, p. 105), todos estes objetivos podem ser alcançados por meio da Educação Ambiental. Na Sala Verde desenvolvida pela Universidade Federal do Ceará, vários cursos são desenvolvidos, tais como: Ecologias de Manguezais; Consumo Sustentável; Reciclagem e Resíduos Sólidos; Educação Sanitária; Ecoturismo e Trilhas Ecológicas; Artesanato com Produtos Naturais; Interpretação de Mapas e Fotografias Áreas; Orientação Geográfica com Uso de Bússola e GPS; A Água no Século XXI; Identidade Cultural.

Ainda conforme Silva, a educação é um processo amplo que não se limita à educação escolar:

Neste sentido, a Sala Verde [...] busca dar suporte teórico-metodológico às escolas, capacitando professores e atuando junto aos alunos através de oficinas temáticas, em que são abordados diversos conteúdos acerca do meio ambiente, sustentabilidade, responsabilidade ambiental, justiça ambiental, noções de cidadania e identidade cultural. (SILVA; RABELO; RODRIGUEZ, 2011, p. 114).

Há diferentes formas de se incluir a temática ambiental nos currículos escolares: atividades artísticas, experiências práticas, produção de materiais e realização de projetos interdisciplinares que conduzem os alunos a serem reconhecidos como agentes ativos no processo que norteia a Educação Ambiental. (SILVA; RABELO; RODRIGUEZ, 2011). 


\section{Educação Ambiental e Turismo em Terras Indígenas}

O turismo é uma atividade vista como alternativa para o desenvolvimento econômico, pois atrai recursos, gera empregos e promove o crescimento regional. Em muitos países, até o ano de 1960, o sucesso do turismo fez com se deixasse de lado os impactos gerados por esta atividade. Os aspectos sociais e ambientais, até aquele momento, não eram tão relevantes quanto o desenvolvimento econômico. (MAURO, 2007).

O turismo mal planejado que vise somente criação de postos de trabalhos, geração de receitas e arrecadação de tributos, pode desencadear impactos negativos no meio ambiente, consumo predatório das paisagens e dos recursos naturais, ocasionando impactos extremamente negativos. Em muitos casos, a exploração turística não se envolve profundamente com o lugar visitado e com a população nativa, sua cultura. Esta acaba sendo a mais prejudicada, pois permanece no local, enquanto os turistas voltam aos seus locais de origem.

Ainda segundo Mauro (2007), os maiores impactos gerados pelo turismo mal planejado seriam:

[...] a poluição sonora, a contaminação dos cursos d'água, o esgotamento de recursos naturais (principalmente a água potável), o desmatamento em função da construção da infra-estrutura turística, a concentração de renda, a exclusão sócio-espacial, o aumento do custo de vida para a população local, o desrespeito com a cultura tradicional das comunidades receptoras, a depredação do patrimônio material e o processo de ocupação desordenada de áreas urbanas (favelização). (MAURO, 2007, p. 17).

Para um turismo bem sucedido, é de vital importância o respeito aos saberes locais, à visão de mundo, aos valores e conceitos, e à ética das comunidades locais. A imposição de saberes e valores externos e de uma dinâmica que não lhes é peculiar, pode causar estranhamentos, choques culturais e de interesses, gerando conflitos e dificuldades de relacionamento entre os diferentes atores que compõem o turismo.

As terras indígenas tem potencial turístico que falam por si, a singularidade de suas sociedades que é autêntica e não estereotipada. Lima e Gita (2007 apud Mauro) enfatizam que o exotismo étnico dos nativos acaba sendo o objeto de interesse do turista, onde, muitas vezes, quanto menor o grau de transformação indígena, maior é a atração despertada no turista.

Silva; Rabelo; Rodriguez (2011), ao abarcarem a temática da Educação Ambiental em terras indígenas por meio do turismo, são enfáticos ao afirmarem que tais ações necessitam de um planejamento estratégico bem definido que oriente as ações da comunidade visando o mínimo de impacto possível na natureza e na cultura da comunidade indígena.

É inevitável que para uma boa Educação Ambiental, sejam implantados programas de treinamento para inserção da população local em atividades que gerem emprego e renda. Estes programas podem ser voltados para a discussão participativa sobre biodiversidade, ecossistemas costeiros e lacustres e diversidade cultural. 


\section{CONSIDERAÇÕES FINAIS}

A Educação Ambiental Indígena no Brasil Colônia foi marcada por imposição, onde os mesmos não possuíam nem mesmo o direito de falar seu próprio idioma. As políticas internacionais de proteção ao indígena, órgãos criados no âmbito nacional e estadual, permitiram às comunidades indígenas romperem com o processo de denominação que perdurava por vários séculos.

Conforme os estudos apresentados, constatou-se que a Educação Ambiental Indígena Brasileira que vem sendo praticada atualmente é, na verdade, uma educação escolar, mas não ambiental. Onde ao longo da história, anda ao lado da religião e doutrinas humanitárias, ocasionado um processo de aculturação.

Conforme a Carta Magna da Educação Brasileira, a educação indígena deveria estar recebendo um tratamento diferenciado em relação ao sistema de ensino brasileiro, devido sua interculturalidade e bilinguismo. Porém, o que se observa é que não há discussão e compreensão, bem menos efetivação da Lei.

As novas tecnologias podem ser usadas como ferramentas midiáticas no ensinoaprendizagem da Educação Ambiental Indígena, pois ajudam a integrar aspectos relativos à cultura e ao Meio Ambiente, superando paradigmas impostos pela visão mecanicista da pedagogia tradicional.

Além das novas tecnologias, há várias alternativas para abordar a Educação Ambiental em terras indígenas. Nesta pesquisa foi discutida as Salas Verdes e o Ecoturismo. As Salas Verdes são ambientes dinâmicos, nelas, acontecem leituras, acesso e vista de documentos, participação de atividades educacionais e a promoção de eventos, além de atividades como cursos, oficinas, palestras e projeção de filmes educativos.

O Ecoturismo pode se transformar numa atividade alternativa para o desenvolvimento econômico, atrai recursos, gera empregos e promove o crescimento regional, mas necessitam de um planejamento estratégico bem definido que oriente as ações da comunidade visando o mínimo de impacto possível na natureza e na cultura da comunidade indígena.

\section{REFERÊNCIAS BIBLIOGRÁFICAS}

1. BURATTO, Lucia Gouvêa. A educação escolar indígena na legislação e os indígenas com necessidades educacionais especiais. Universidade Estadual de Londrina. 2007.

2. MAURO, Victor Ferri. Turismo em Terra Indígena: O caso da Reserva Pataxó da Jaqueira. Universidade de Brasília. 2007.

3. PUPPI, Edi Ema S. Do mito ao livro: escolas bilíngues em língua Kaingang. Dissertação de Mestrado. PUC, 1996.

4. RIBEIRO, Rúbia S. Lelis et al.li. Lei de Diretrizes e Bases da Educação Nacional Lei N. 9394/96. 2000. 
5. BRASIL, Congresso Nacional. Constituição: República Federativa do Brasil. Brasília: Ministério da Educação. 1988.

6. BRASIL. Lei № 9.394 de 20 de dezembro de 1996. Lei de Diretrizes e bases da educação nacional. Brasília, Congresso Nacional, 1996.

7. BRASIL. Lei № 9.795 de 27 de abril de 1999. Política Nacional de Educação Ambiental. Brasília, Congresso Nacional, 1999.

8. BRASIL. Lei № 10.172 de 09 de janeiro de 2001. Plano nacional de educação. Brasília, Congresso Nacional, 2001.

9. FERREIRA, Mariana Kawal. A educação escolar indígena: um diagnóstico crítico da situação no Brasil. In SILVA, Aracy Lopes da Silva e Ferreira, Mariana Kawall (orgs) Antropologia, História e Educação: A questão indígena e a escola. São Paulo: FAPESP/GLOBAL/MARI, 2001.

10. GALLOIS, Dominique Tilkin; GRUPONI, Denise Fajardo. Povos Indígenas no Amapá e Norte do Pará: quem são, onde estão, quantos são, como vivem e o que pensam? São Paulo: IEPÉ/Museu do Índio. 2009. ISBN 85-98046-01-9.

11. Morin, Edgar - Os sete Saberes Necessários à Educação do Futuro. São Paulo: Cortez; Brasília, DF: UNESCO, 2011. ISBN: 978-85-249-1754-7.

12. REIGOTA, Marcos. O que é educação ambiental. São Paulo: Brasiliense, 2012. 2ㅇe ed. ISBN: 978-85-11-00122-9.

13. SILVA, Edson Vicente da; RABELO, Francisco Braz; RODRIGUEZ, José M. Mateo (Org.). Educação Ambiental e Indígena: caminhos da extensão universitária na gestão de comunidades tradicionais. Fortaleza: Edições UFC, 2011. ISBN: 978-85-7282-430-9. 